\title{
3D-printed model in the guidance of tumor resection: a novel concept for resecting a large submucosal tumor in the mid-esophagus
}

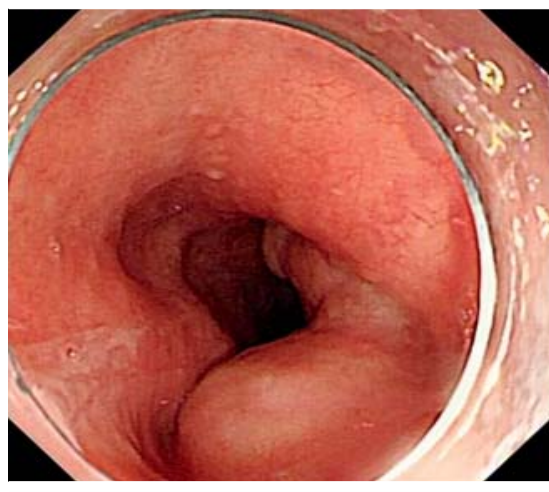

- Fig. 1 The submucosal tumor in the mid-esophagus, as shown by endoscopy.

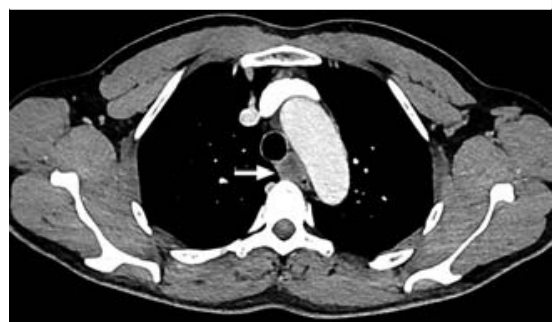

- Fig. 2 The submucosal tumor (arrow) and its adjacent organs, as shown by computed tomography.

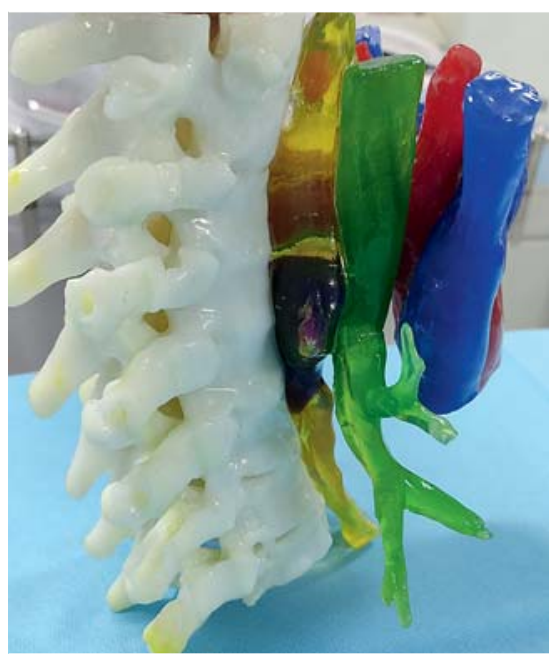

Fig. 3 The submucosal tumor and its adjacent organs, as shown by 3D-printed model.
Although most large submucosal tumors in the esophagus such as leiomyomas are benign, obstructive symptoms may develop owing to their size [1]. Endoscopic resection of large tumors in the esophagus remains difficult [2], and exophytic tumors in the mid-esophagus are the worst. The main problem is the presence of important adjacent organs such as bronchus, aorta, and spine. We report a novel concept for facilitating endoscopic resection: 3D-printed model in the guidance of tumor resection (3DM-GTR). The 3D-printed model, based on enhanced computed tomography, could clearly display the tumor anatomy and details of adjacent structures, playing a role in planning and implementing endoscopic resection.

A 47-year-old man with intermittent dysphagia for 2 months was diagnosed with a large submucosal tumor in the midesophagus ( Fig.1). Enhanced computed tomography showed that the lesion was close to the bronchus, aorta, and spine (-Fig.2). The 3D-printed model directly demonstrated the tumor and its adjacent organs ( $>$ Fig. 3 ). Under the guidance of the model ( $\triangleright$ Video 1 ), we successfully resected the tumor ( Fig.4), without obvious intraoperative bleeding or other injuries to adjacent organs ( $\triangleright$ Fig.5). The mucosal entry was closed using endoclips. The pathology confirmed the diagnosis of leiomyoma.

Fasting and prophylactic antibiotics were prescribed for 2 days. Proton pump inhibitors and nutritional support were given. The mild cervical subcutaneous emphysema detected during the procedure resolved spontaneously. The patient began drinking after 3 days and was discharged on postoperative Day 5 . At 3-month follow-up, the patient had not experienced discomfort and upper endoscopy confirmed healing of the mucosa.

3DM-GTR seems a good and promising method, especially for large tumors in complex locations. The simulation model can remind the endoscopist in real time about what to expect in the next step; thus, it could reduce unexpected injuries to important adjacent organs.

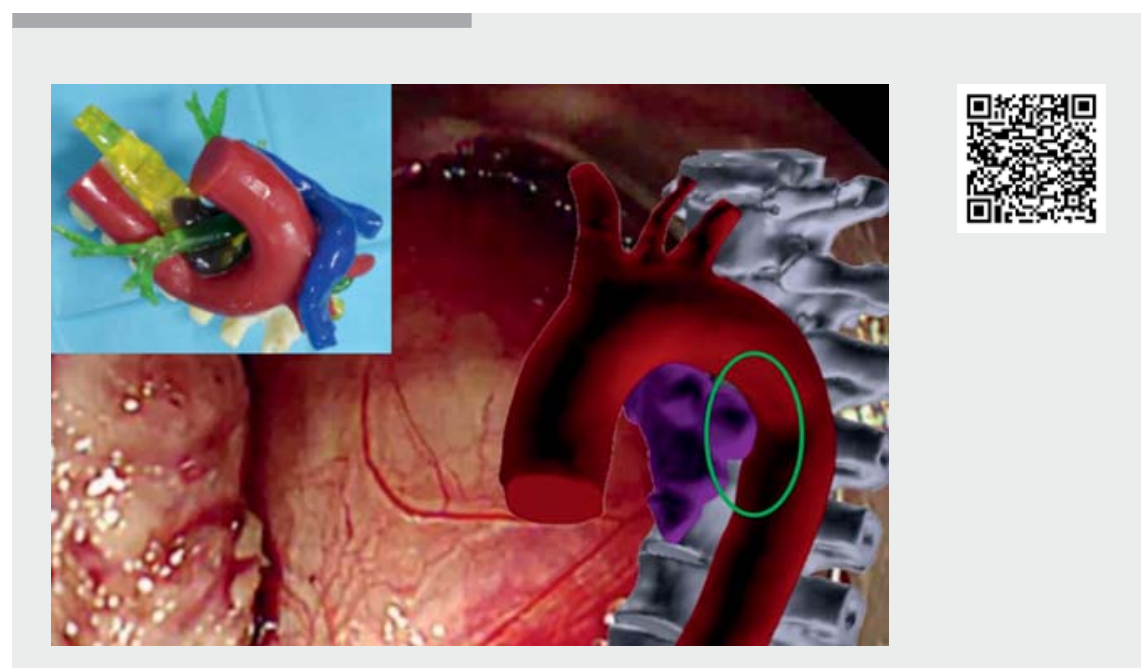

$\checkmark$ Video 13 D-printed model in the guidance of endoscopic resection of a large submucosal tumor in the mid-esophagus. 


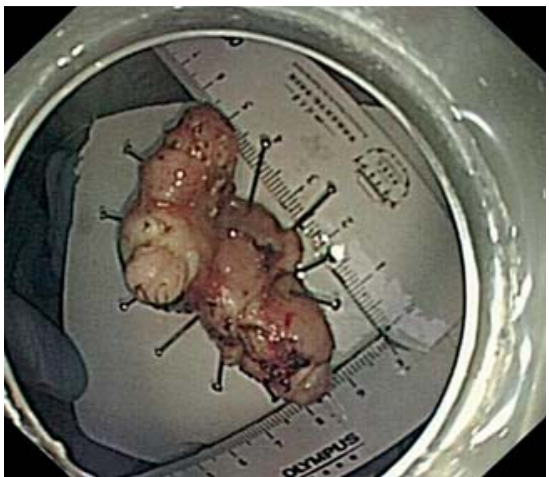

> Fig. 4 The resected tumor.

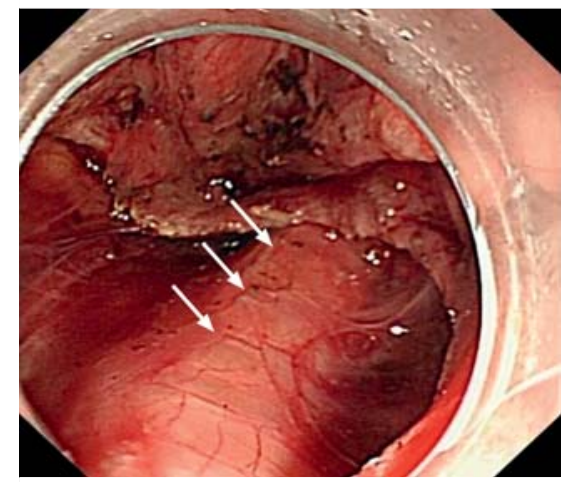

Fig. 5 The exposed aorta after tumor resection (arrows).
Endoscopy_UCTN_Code_TTT_1AO_2AN

\section{Acknowledgment}

We acknowledge the support from Sichuan Province Science and Technology Department (China) (2017SZ0009).

\section{Competing interests}

The authors declare that they have no conflict of interest.

\section{The authors}

Liansong Ye, ", Dan Yang2, ", Yong Huang ${ }^{3}$, Ke Liao', Xianglei Yuan ${ }^{1}$, Bing Hu${ }^{1}$

1 Department of Gastroenterology, West China Hospital, Sichuan University, Chengdu, Sichuan, China

2 Department of Radiology, West China Hospital, Sichuan University, Chengdu, Sichuan, China

3 Sichuan Farsoon Turing Additive Manufacturing Technology Co., Ltd., Chengdu, Sichuan, China

\section{Corresponding author}

\section{Bing Hu, MD}

West China Hospital, Sichuan University, No. 37 Guo Xue Alley, Wu Hou District, Chengdu City, 610041, Sichuan Province, China

Fax: +86-28-85423387

hubingnj@163.com

\section{References}

[1] Rijcken E, Kersting CM, Senninger $\mathrm{N}$ et al. Esophageal resection for giant leiomyoma: report of two cases and a review of the literature. Langenbecks Arch Surg 2009; 394: 623-629

[2] Ye L, Sharma M, Yang D et al. Open dissection for resection of a large submucosal tumor in the esophagus. Endoscopy 2019; 51: E243-E244

\section{Bibliography}

DOI https://doi.org/10.1055/a-1090-6940

Published online: 29.1.2020

Endoscopy 2020; 52: E273-E274

(C) Georg Thieme Verlag KG

Stuttgart · New York

ISSN 0013-726X

\section{ENDOSCOPY E-VIDEOS}

https://eref.thieme.de/e-videos

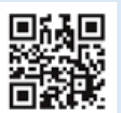

Endoscopy E-Videos is a free access online section, reporting on interesting cases and new techniques in gastroenterological endoscopy. All papers include a high quality video and all contributions are freely accessible online.

This section has its own submission website at

https://mc.manuscriptcentral.com/e-videos

\footnotetext{
* These authors contributed equally to this work.
} 